\title{
Evaluation of depression and anxiety during the first trimester
}

\section{ilk trimestrda depresyon ve anksiyetenin değerlendirilmesi}

\author{
Hatice YILMAZ DOĞRU, Asker Zeki ÖZSOY, Elif GÖZDEMIR, Selim GÜLÜCÜ, Fazlı DEMIRTÜRK
}

\begin{abstract}
The aim of this study was to evaluate the incidence of depression and anxiety in the first trimester which affect both mother and baby and may lead to serious problems, and also assess its association with obstetric history. One hundred and ninety seven pregnants were included in the study. Pregnants with a past or current history of affective or anxiety disorder, chronic systemic disease, pregnants with the aid of assisted reproductive techniques, with malfomations diagnosed by ultrasonography, hyperemesis gravidarum and those with multiple pregnancy were excluded. Beck Depression Inventory (BDE) and Beck Anxiety Inventory (BAE) were used for evaluating the level of depression and anxiety of the subjects. Demographic values including age, parity, gravida, number of abortus and live births of the patients were recorded. BAE and BDE values were compared after the patients were grouped according to the presence of abortus, gravida, and the number of live births. A total of 49 (25.1\%) patients required medical treatment for depression according to a cut-off value of 17 for Beck Depression Inventory. The mean BAE score of all enrolled patients was $11.91 \pm 9.47$ points. Anxiety disorder was found in $49.2 \%$ of pregnants. In conclusion, negative effect of depression and anixety during pregnancy on fetal and maternal health has been indicated in the literature. We think that that an efficient examination in the first trimester of pregnancy may enable diagnosis of affective disorders in the early stage, and consequently an appropriate treatment will prevent their negative effects on fetal and maternal health.
\end{abstract}

Key words: Depression, beck anxiety inventory, beck depression inventory, first trimester öz

Bu çalışmadaki amacımız, hem anneyi hem de bebeği etkileyen ve ciddi sorunlara yol açabilen depresyon ve anksiyetenin birinci trimestrda görülme oranlarını ve obstetrik öykü ile olan ilişkisini incelemektir. Çalış̧maya 197 gebe dâhil edildi. Geçmişinde anksiyete ve affektif bozukluğu olan ya da şu anda aktif anksiyete ve affektif bozukluğu olan gebeler, kronik sistemik hastalığı olanlar, yardımcı üreme yöntemleri ile gebe kalanlar, ultrasonografide malformasyon tespit edilenler, hiperemezis gravidarum ve çoğul gebeliği olanlar çalışma dışı bırakıldı. Olguların depresyon ve anksiyete düzeylerinin değerlendirilmesi için Beck Depresyon Envanteri (BDE) ve Beck Anksiyete Envanteri (BAE) kullanıldı. Hastaların yaş, parite, gebelik sayısı, abortus sayısı ve yaşayan çocuk sayısını içeren demografik verileri kaydedildi. Hastalar abortus yapıp yapmadıklarına, gebelik sayısına, canlı çocuk sayısına göre sınıflandırılarak $B D E$ ve $B A E$ değerlendirilmelerinden elde edilen puanlar karşılaştırıldı. Beck Depresyon Envanteri için sınır değer 17 olarak kabul edildiğinde tedaviye gereksinim duyacak depresyonun 49 hastada $(\% 25,1)$ var olduğu izlendi. Çalışmaya alınan

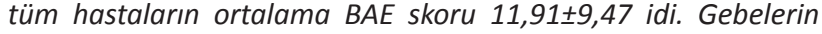
$\% 49,2$ 'sinde anksiyete bozukluğu tespit edildi. Sonuç olarak, gebelikte izlenen depresyon ve anksiyetenin fetal ve maternal sağığı negatif yönde etkileyebileceği literatürde belirtilmiştir. Gebeliğin birinci trimestrında yapılacak olan uygun değerlendirmeler ile, affektif bozuklukların tanısının erken dönemde yapılabileceği ve böylece uygun tedavisi ile fetal ve maternal sağlık üzerine olan olumsuz etkilerinin önlenebileceğini düşünmekteyiz.

Anahtar kelimeler: Depresyon, beck anksiyete envanteri, beck depresyon envanteri, ilk trimester

\section{GíRiş}

Depresyon, kişinin kendisini derin üzüntülü bir duygu durum içerisinde hissettiği, yaşama istek ve zevkinin kaybolduğu, konuşma ve hareketlerde yavaşlamanın görüldüğü, kişinin kendini değersiz, güçsüz ve isteksiz hissettiği, ölüm düşüncesinin yoğun yaşandığı hatta intihar girişiminin bile görülebildiği, uyku, iştah, cinsel istek ile ilgili fizyolojik bozuklukların olduğu bir hastalıktır ${ }^{1}$. Anksiyete ise nedeni belli olmayan iç sıkıntısı ve kayg şeklinde de adlandırılan kişiyi rahatsız edici, endişe ve korku duygusudur. İçsel ya da dış dünyadan bir tehlike olasılığı ya da kişi tarafından tehlikeli olarak algılanıp yorumlanan herhangi bir durum karşı-

Bu çalışmanın bir kısmı 12. Ulusal Jinekoloji ve Obstetrik Kongresi (6. Akdeniz Ülkeleri Jinekoloji ve Obstetrik Federasyonu Kongresi)'nde poster olarak sunulmuştur.

Received: 02.11 .2015

Accepted: 02.12 .2015

Gaziosmanpaşa Üniversitesi Tıp Fakültesi, Kadın Hastalıkları ve Doğum Anabilim Dalı

Yazışma adresi: Hatice Yılmaz Doğru, Gaziosmanpaşa Üniversitesi Tıp Fakültesi, Kadın Hastalıkları ve Doğum Anabilim Dalı, Tokat e-mail: hatice_yilmaz47@hotmail.com 
sında yaşanan duygu durumdur ${ }^{2}$.

Gebelik sırasında anne hem kendi açısından hem de bebek açısından nasıl bir dönem geçireceği endişesiyle duygu dalgalanmaları yaşayabilmektedir. Artık eski inanışın aksine gebeliğin depresyon ve anksiyeteye karşı koruyucu etkisi bulunduğu düşüncesinden uzaklaşılmıştır. Aksine bu dönemdeki fizyolojik ve psikososyal değişiklikler depresyon ve anksiyeteye zemin hazırlayabilmektedir ${ }^{3,4}$.

Literatüre bakıldığında yapılan çalışmalarda antenatal depresyon oranlarının \%4,8 ile \%40 arasında değiştiği belirlenmiştir. Bundan dolayı birkaç profesyonel organizasyon depresyonun antenatal muayene sırasında ve gebeliğin her trimesterinde rutin olarak taranmasını önermektedir ${ }^{5-8}$.

Gebelik sırasında geçirilen depresyon ve anksiyete maternal ve fetal komplikasyonlara neden olabilmektedir ${ }^{9}$. Yaşanan antenatal stresin; plasental, maternal pitüiter, adrenal aksın aktivasyonu ile preterm doğuma neden olduğu bildirilmiştir. Aynı zamanda gebelik hipertansiyonu ve preeklampsi için önemli bir risk faktörüdür. Yine gebelik depresyonu ve anksiyetesi postpartum depresyon ve anksiyete gelişimi için çok önemli bir risk faktörüdür. Gebelik sırasında depresyon ve anksiyete yalnızca gebe için değil henüz anne karnındaki bebek içinde bir stres kaynağı olup, postnatal yaşamda da nöromotor va davranışsal gelişimi olumsuz yönde etkilemektedir. Bu annelerden doğan bebeklerin daha düşük doğum ağırlığına sahip oldukları bildirilmiştir ${ }^{4,10,11}$.

Bu çalışmadaki amacımız hem anneyi hem de bebeği etkileyen, ciddi sorunlara yol açabilen ve önemli bir toplum sağlığı sorunu olan depresyon ve anksiyetenin birinci trimestrda görülme oranlarını ve obstetrik öykü ile olan ilişkisini incelemektir.

\section{GEREÇ ve YÖNTEM}

Çalışma için Gaziosmanpaşa Üniversitesi Tıp Fakültesi Klinik Araştırmalar Etik Kurul onayı (14-KAEK-064) alındıktan sonra, Kadın Hastalıkları ve Doğum AD
Polikliniğimize Nisan 2014 ile Temmuz 2014 tarihleri arasında başvuran, gebelik haftası 11-14 hafta arasında olan 197 gebe dâhil edildi. Geçmişinde anksiyete ve affektif bozukuluğu olan ya da şu anda aktif anksiyete ve affektif bozukluğu olan gebeler, kronik sistemik hastalığı olanlar, yardımcı üreme yöntemleri ile gebe kalanlar, ultrasonografide malformasyon tespit edilenler, hiperemezis gravidarum ve çoğul gebeliği olanlar çalışma dışı bırakıldı. Gebelik haftaları ultrasonografik olarak belirlendi. Olguların depresyon ve anksiyete düzeylerinin değerlendirilmesi için Beck Depresyon Envanteri (BDE) ile Beck Anksiyete Envanteri (BAE) kullanıldı. Araştırmacılar tarafından polikliniğe gelen gebelere, araştırma hakkında bilgi verilip, araştırmaya katılmayı kabul eden gebelere yüz yüze görüşme yöntemi ile anketler dolduruldu.

Hastaların yaş, parite, gebelik sayısı, abortus sayısı, yaşayan çocuk sayısını içeren demografik verilerin yanında BDE'nin total puanlaması ve depresif yakınmaların affektif komponentini değerlendiren ilk 13 sorunun puanlaması, somatik komponenti değerlendiren son 8 sorunun puanlaması ile birlikte BAE'nin puanlaması kaydedildi. Hastalar abortus yapıp yapmadıklarına, gebelik sayısına, canlı çocuk sayısına göre sınıflandırılarak BDE ve BAE değerlendirilmelerinden elde edilen puanlar karşılaştıııldı.

Beck Depresyon Envanteri; erişkinlerde depresyon riskini, depresif belirtilerin düzeyini ve şiddet değişimini ölçmek üzere geliştirilmiştir. Türkçe geçerlik ve güvenirlik çalışması Hisli tarafından yapılmış ve ölçeğin sınır değeri 17 olarak belirlenmiştir. Ölçekten alınacak toplam puan 0-63 arasında değişmektedir ${ }^{12}$. Scalza ve ark.'nın ${ }^{13}$ çalışmalarında belirtildiği gibi, hastaların verdikleri yanıtlardan elde edilen puanlara göre, 10-16 puan hafif ruhsal sıkıntı, 17-29 sınırda klinik depresyon, 21-30 puan orta seviyede depresyon, 31-40 ciddi seviyede depresyon, $>41$ puan çok ciddi seviyede depresyon olarak sınıflandırıldı. Aynı çalışmada belirtildiği gibi, ilk 13 soru affektif son sekiz soru ise somatik semptomlar ile ilişkilendirildi.

Beck Anksiyete Envanteri, Beck ve ark. (1988) tarafından geliştirilen bireylerin yaşadığı anksiyete be- 
lirtilerinin sıklığının belirlenmesi amacıyla kullanılan kendini değerlendirme ölçeğidir. Toplam 21 maddeden oluşan, 0-3 arası puanlanan likert tipi bir ölçektir. Türkiye'de geçerlik ve güvenirliği Ulusoy ve ark. ${ }^{14}$ (1998) tarafından yapılmıştır. Hastaların verdikleri yanıtlardan elde edilen puanlar Julian' $n ı n^{15}$ çalışmasında belirttiği gibi $<10$ puan normal, $10-18$ puan hafif anksiyete, 19-29 puan orta düzeyde anksiyete, 30-63 puan ciddi anksiyete olarak sınıflandırıldı.

Kalitatif veriler sayı ve yüzde olarak, kantitatif veriler ise ortalama ve standart sapma olarak gösterildi. íkili grupların karşılaştırılmasında Mann-Whitney U testi uygulandı. Hastalardan elde edilen veriler incelenirken Statistical Package for Social Sciences (SPSS) 20.0 programı kullanıldı. Tüm analizlerde, istatistik anlamlılık düzeyi $p<0.05$ olarak kabul edildi.

\section{BULGULAR}

Çalışmaya alınan 197 gebenin yaşları 18 ile 41 arasında değişmekle birlikte yaş ortalaması $26 \pm 5,28$ idi. Çalışma grubu obstetrik öykülerine göre değerlendirildiğinde, gebelik sayısı bir ile yedi aralığında değişmekte olup, gebelik sayısı için median değer iki idi. Doğum sayılarına bakıldığında doğum sayısı sıfır ile altı arasında değişmekte olup doğum sayısı için median değer bir idi. Gebelerin \%45,2'sinin ( $n=89$ ) yaşayan çocuğu yok iken, $\% 54,8^{\prime}$ inin $(n=108)$ en az bir yaşayan çocuğu vardı. Gebelerin $\% 24,9^{\prime}$ unda $(n=49)$ abortus öyküsü mevcuttu.
Beck depresyon envanteri için sınır değer 17 olarak kabul edildiğinde, tedaviye gereksinim duyacak depresyon varlığının 49 hastada $(\% 25,1)$ bulunduğu saptandı. Çalışmaya katılan tüm gebelerin Beck Depresyon Envanteri skorlarının dağılımı Tablo 1'de gösterilmiştir.

Çalışmaya alınan tüm hastaların anksiyete skorları değerlendirildiğinde ortalama Beck Anksiyete Skoru $11,91 \pm 9,47$ idi. Gebelerin \%49,2'sinde anksiyete bozukluğu tespit edildi. Tüm gebelerin Beck Anksiyete Envanteri skorlarının dağılımı Tablo 2'de gösterilmiştir.

Depresyon ve anksiyetenin obstetrik öykü ile olan ilişkisine bakıldığında toplam BDE puanlamasında fark bulunmazken, son sekiz sorunun skoruna göre bakıldığında abortus yapanlarda abortus yapmamış-

Tablo 1. Beck Depresyon Envanteri toplam puan dağılımı.

\begin{tabular}{lcc}
\hline & $\mathbf{n}$ & $\%$ \\
\hline Normal (1-10 PUAN) & 98 & 50,3 \\
Hafif Ruhsal Sıkınt (11-16 PUAN) & 48 & 24,6 \\
Sınırda Klinik Depresyon (17-20 PUAN) & 14 & 7,1 \\
Orta Seviyede Depresyon (21-30) & 25 & 12,7 \\
Ciddi Seviyede depresyon (31-40) & 9 & 4,6 \\
Çok Ciddi Seviyede Depresyon (>41) & 1 & 0,5 \\
\hline
\end{tabular}

Tablo 2. Beck Anksiyete Envanterinin puanlama dağılımı.

\begin{tabular}{lcc}
\hline & $\mathbf{n}$ & $\%$ \\
\hline Normal & 100 & 50,8 \\
Hafif Anksiyete(10-18) & 58 & 29,4 \\
Orta Anksiyete(19-29) & 30 & 15,2 \\
Ciddi Anksiyete(30-63) & 9 & 4,6 \\
\hline
\end{tabular}

Tablo 3. Beck Anksiyete ve Beck Depresyon envanterleri puanlamasının gebelerin obstetrik öykülerine göre karşılaştırılması.

\begin{tabular}{|c|c|c|c|c|}
\hline & BAE & BDE-13 & BDE-8 & BDE-T \\
\hline Bir gebeliği olan gebeler $(n=75)$ & $12,02 \pm 9,16$ & $5,98 \pm 5,50$ & $4,77 \pm 4,07$ & $11,05 \pm 8,88$ \\
\hline Birden fazla gebeliği olanlar ( $n=122)$ & $11,78 \pm 9,65$ & $6,74 \pm 5,74$ & $6,10 \pm 4,37$ & $12,94 \pm 9,42$ \\
\hline$P$ & 0,710 & 0,387 & $0,026 *$ & 0,157 \\
\hline Abortus yapmış olanlar $(n=49)$ & $11,00 \pm 9,25$ & $7,64 \pm 6,06$ & $6,64 \pm 4,16$ & $14,29 \pm 9,88$ \\
\hline Abortus yapmamış olanlar $(n=148)$ & $12,16 \pm 9,52$ & $6,06 \pm 5,47$ & $5,25 \pm 4,16$ & $11,53 \pm 8,96$ \\
\hline $\mathrm{P}$ & 0,577 & 0,088 & $0,044^{*}$ & 0,113 \\
\hline Yaşayan çocuğu olanlar (n=108) & $12,06 \pm 9,23$ & $6,55 \pm 5,51$ & $6,12 \pm 4,36$ & $12,77 \pm 9,16$ \\
\hline Yaşayan çocuğu olmayanlar $(n=89)$ & $11,64 \pm 9,66$ & $6,32 \pm 5,84$ & $4,95 \pm 4,17$ & $11,53 \pm 9,35$ \\
\hline $\mathrm{P}$ & 0,971 & 0,686 & 0,066 & 0,256 \\
\hline
\end{tabular}

BAE:Beck Anksiyete Envanteri, BDE-13 Beck Depresyon Envanteri ilk 13 sorunun skoru, BDE-8 Beck Depresyon Envanteri son 8 sorunun skoru, BDE-T Beck Depresyon Envanteri toplam skor 
lara göre BDE puanlaması istatistiksel olarak daha anlamlı yüksek bulundu $(p=0,044)$. Yine birden fazla gebeliği olanlarda da BDE son sekiz sorunun skorlaması bir gebeliği olanlara göre daha yüksek bulundu ( $p=0,026$, Tablo 3).

\section{TARTIŞMA}

Gebelik süresince görülen depresif bozukluklar hem fetal hem de maternal sağlığı oldukça etkileyen hastalıklar olarak bilinmektedir ${ }^{16}$. Yapılan çalışmalarda, tedavi edilmeyen olgularda obstetrik ve doğumsal komplikasyonların görülebileceği gösterilmiştir ${ }^{17,18}$. Gebeliğin indüklediği hipertansif hastalıklar bu obstetrik komplikasyonların başında gelir, bununla birlikte abortus, antenatal kanama, uterin arterde direnç artışı, düşük APGAR skoru, düşük doğum ağırlığı, yenidoğan yoğun bakım ünitesine gereksinim duyan bebek doğurma ve prematüre doğum diğer komplikasyonlardandır ${ }^{18}$. Ayrıca gebelik süresince izlenen depresyon \%50-62 oranında postpartum depresif bozukluk ile de ilişkilidir ${ }^{19}$.

Literatür incelendiğinde depresyonun gebelik süresince olan sıklığı \%5-51 arasında değiştiği tespit edilmiştir ${ }^{16,20,21}$. Kurki ve ark. ${ }^{21}$ yaptıkları bir çalışmada, gebelikte depresyon oranı \%30, Markus ve ark. ${ }^{20}$ yaptıkları çalışmada ise $\% 20$ bulunmuştur. Bennet ve ark. ${ }^{22}$ gebeliğin farklı dönemlerinde depresyon prevelansını inceledikleri çalışmada, birinci trimestrda depresyon oranını \%7,4 olarak belirtmişlerdir. Yücel ve ark. ${ }^{23}$ ilk trimestrda olan 111 hastayı değerlendirdikleri çalışmada ise, depresif bozukluk oranını \%20 olarak bulmuşlardır. Çalışmamızda ise tedaviye gereksinim duyacak depresyon oranı literatür ile uyumlu olacak şekilde $\% 25,1$ olarak tespit edildi.

Gebelik bir kadının yaşamında birçok hormonal, fiziksel, psikososyal değişikliklerin yaşandığı, anksiyete ve stress oluşturabilecek bir çok durum ile karşılaşabileceği önemli bir dönemdir ${ }^{24}$. Literatür incelendiğinde farklı oranlarda anksiyete oranları rapor edilmiştir. Yücel ve ark. ${ }^{23}$ daha önceden psikiyatrik hastalığı olmayan, gebeliğin birinci trimestrında olan, PRIMEMD ölçeği kullanarak 111 gebeyi inceledikleri bir ça-
Iışmada, gebelerin \%21,6'sında hem anksiyete hem de depresif bozukluklar tespit etmişler iken, \%13,5 oranında anksiyete bozukluğu ve toplam olarak gebelerin \%35,1'inde anksiyete bozukluğu tespit etmişlerdir. Çakır ve ark. ${ }^{25}$ hastane anksiyete ve depresyon ölçeği kullanarak 173 gebe kadını değerlendirdikleri çalışmada ise, anksiyete oranını \%34,1 olarak bulmuşlardır. Lee ve ark. ${ }^{26}$ yaptıkları çalışmada, gebelerin \%54'ünde anksiyete saptadıklarını rapor etmişlerdir. Bizim çalışmamızda ise gebelerin \%49,2'sinde anksiyete tespit edildi. Hafif anksiyete $\% 29,2$, orta şiddette $\% 15,2$, ciddi olan $\% 4,6$ olarak bulundu.

Obstetrik öykü gebelik süresince görülen depresyon ve anksiyete için risk faktörüdür. Çakır ve ark. ${ }^{25}$ 173 gebe kadını değerlendirdikleri çalışmalarında, gebelik sayısı arttıkça depresyon skorunun arttığını ancak anksiyete skorunda bir değişiklik olmadığını saptamışlardır. Akbaş ve ark. ${ }^{27}$ yaptıkları çalışmada ise, birinci gebeliği olan kadınlarda daha fazla kaygı durumu saptamışlar iken, daha az depresif durum saptadıklarını belirtmişlerdir. Çalışmamızda gebelik sayısı ile anksiyete skoru arasında bir ilişki tespit edilememiş iken, birden fazla gebelik deneyimi yaşamış olan kadınların somatik-performans durumunu ölçen BDE'nin son 8 sorusunun skoru istatistiksel olarak anlamlı derecede yüksek olduğu tespit edildi. Çalışmadan elde edilen sonuç, birden fazla gebelik deneyimi yaşamış olan kadınlarda somatik performansı etkileyebilecek düzeyde bir depresyon varlığının olabileceğini göstermektedir. Ancak, literatür incelendiğinde BDE'nin gebeler için somatik-performans ve kognitifaffektif komponentlerini ayrı bir şekilde inceleyen bir çalışmaya rastlanmamıştır. Bu da bize bu konuyla ilgili daha ileri çalışmalar gerektiğini göstermektedir. Bunula birlikte, toplam depresyon skorlarında anlamlı bir fark tespit edilmedi.

Çalışkan ve ark.'nın ${ }^{28} 198$ kadını inceledikleri bir çaIışmada, düşük sayısı, BDE skoru arasında pozitif bir korelasyon tespit etmişlerdir. Julie Mc Farland ve ark. ${ }^{29}$ major depresif olan ve olmayan gebe kadınları karşılaştırdıkları çalışmada ise, perinatal fetal kayıp bakımından anlamlı fark bulamamışlardır. Bizim çalışmamızda ise toplam BAE ve toplam BDE skorları daha 
önceden düşük yapan ve yapmayan kadınlar arasında benzer iken, beck depresyon envanterinin affektif durumu değerlendiren son 8 sorusunun skoru, düşük öyküsü olan grupta anlamlı olarak daha yüksek bulundu. Yine Farland ve ark. ${ }^{29}$ yaptığı çalışmada, depresif gebe kadın grubunda depressif olmayan gebelere göre ortalama yaşayan çocuk sayısı daha fazla tespit edilmiştir. Bizim çalışmamızda ise, çocuk sayısı ile anksiyete ve depresyon skorları arasında bir ilişki izlenmemiştir. Bu farklıı̆ı̆ın, değerlendirme için yapılan testlerin farklılığından kaynaklanmış olabileceğini düşünmekteyiz.

Bu çalışmanın bazı eksikleri mevcuttur. Birincisi, anksiyete ve depresyon düzeylerini etkileyen faktörlerden olan maddi gelir, eğitim düzeyi ve sosyokültürel düzeylerinin değerlendirilmemiş olması, çalışma grubundaki gebelerin bu açılardan homojen olmamasına ve buna bağlı olarak sonuçların etkilenmesine yol açmış olabilir. İkincisi, çalışma grubu ile yakın özelliklere sahip, gebe olmayan bir kontrol grubunun olması, tek başına gebeliğin depresyon ve anksiyete skorları üzerine olan etkisinin daha detaylı bir şekilde incelenmesini sağlayabilirdi.

Sonuç olarak, gebelikte izlenen depresyon ve anksiyetenin fetal ve maternal sağlığı etkilebileceği literatürde belirtilmiştir. Gebeliğin birinci trimestrı gibi erken bir dönemde yapılacak olan uygun değerlendirmeler ile, saklı kalmış anksiyete ve depresyon bozuklukları uygun bir tarama metodu ile ortaya çıkarılabilir ve doğru tedavi ile bu klinik tabloların fetal ve maternal sağlık üzerine olan olumsuz etkilerinin önlenebileceğini düşünmekteyiz. Ancak, yalnızca gebeliğin anksiyete ve depresyon skorlarının üzerine etkisini daha net bir şekilde ortaya koyabilmek için fazla sayıda olgu içeren randomize kontrollü çalışmalara gereksinim vardır.

\section{KAYNAKLAR}

1. Sağduyu A, Ögel K, Özmen E, et al. Birinci basamak sağlık hizmetlerinde depresyon. Turk Psikiyatri Derg 2000;11:3-16.

2. Işık E, Taner Y. Çocuk, Ergen ve Erişkinlerde Anksiyete Bozuklukları. Asimetrik Parelel Kitabevi, 2006; 3-29.

3. Vırıt O, Akbaş E, Savaş HA, et al. Gebelikte depresyon ve kaygı düzeylerinin sosyal destek ile ilişkisi. Noropsikiyatri Arşivi
2008;45:9-13.

4. Marakoğlu K, Şahsıvar MŞ. Gebelikte depresyon. Turkiye Klinikleri J Med Sci 2008;28:525-532.

5. Leigh B, Milgrom J. Risk factors for antenatal depression, postnatal depression and parenting stress. BMC Psychiatry 2008;8:24.

http://dx.doi.org/10.1186/1471-244X-8-24

6. Qiao YX, Wang J, Li J, et al. The prevalence and related risk factors of anxiety and depression symptoms among Chinese pregnant women in Shanghai. Aust N Z J Obstet Gynaecol 2009;49:185-190.

http://dx.doi.org/10.1111/j.1479-828X.2009.00966.x

7. Bödecs $T$, Horváth $B$, Kovács $L$, et al. Prevalence of depression and anxiety in early pregnancy on a population based Hungarian sample. Orv Hetil 2009;150:1888-1893.

http://dx.doi.org/10.1556/OH.2009.28712

8. American College of Obstetricians and Gynecologists Committee on Health Care for Undeserved Women. ACOG Committee Opinion No. 343: psychosocial risk factors: perinatal screening and intervention. Obstet Gynecol 2006;108:469477.

http://dx.doi.org/10.1097/00006250-200608000-00046

9. Chung TK, Lau TK, Yip AS, et al. Antepartum depressive symptomatology is associated with adverse obstetric and neonatal outcomes. Psychosom Med 2001;63:830-4. http://dx.doi.org/10.1097/00006842-200109000-00017

10. Muzik M, Marcus SM, Heringhausen JE, et al. When depression complicates child bearing:guidelines for screening and treatment during antenatal and postpartum obstetric care. Obstet Gynecol Clin North Am 2009;36:771-88. http://dx.doi.org/10.1016/j.ogc.2009.10.006

11. Bowen A, Muhajarine N. Antenatal depression. Canadian Nurse Journal 2006;102:26-30.

12. Hisli N. Beck Depresyon Envanteri'nin geçerliliği üzerine bir çalışma. Psikoloji Dergisi 1988;6:118-122.

13. Scalzo P, Kummer A, Cardoso F, et al. Depressive symptoms and perception of quality of life in Parkinson's disease. Arq Neuropsiquiatr 2009;67:203-8. http://dx.doi.org/10.1590/S0004-282X2009000200006

14. Ulusoy M, Sahin, N, Erkmen H. Turkish version of the Beck Anxiety Inventory; Psychometric Properties. Journal of Cognitive Psychotherapy 1998;12:163-172.

15. Julian LJ. Measures of anxiety: State-Trait Anxiety Inventory (STAI), Beck Anxiety Inventory (BAI), and Hospital Anxiety and Depression Scale-Anxiety (HADS-A) Arthritis Care Res (Hoboken) 2011;63:467-72.

http://dx.doi.org/10.1002/acr.20561

16. Chung TK, Lau TK, Yip AS, et al. Antepartum depressive symptomatology is associated with adverse obstetric and neonatal outcomes. Psychosom Med 2001;63:830-4. http://dx.doi.org/10.1097/00006842-200109000-00017

17. Sandman CA, Wadhwa PD, Dunkel-Schetter C, et al. Psychobiological influences of stress and HPA regulation on the human fetus and infant birth outcomes. Ann N Y Acad Sci 1994;739:198-210. http://dx.doi.org/10.1111/j.1749-6632.1994.tb19822.x

18. Dorn LD, Susman EJ, Petersen AC. Cortisol reactivity and anxiety and depression in pregnant adolescents: a longitudinal perspective. Psychoneuroendocrinology 1993;18:219-39. http://dx.doi.org/10.1016/0306-4530(93)90006-7

19. Evans J, Heron J, Francomb H, et al. Cohort study of depressed mood during pregnancy and after childbirth. BMJ 2001;323:257-60.

http://dx.doi.org/10.1136/bmj.323.7307.257 
20. Marcus SM, Flynn HA, Blow FC, et al. Depressive symptoms among pregnant women screened in obstetrics settings. $J$ Womens Health (Larchmt) 2003;12:373-80. http://dx.doi.org/10.1089/154099903765448880

21. Kurki T, Hiilesmaa V, Raitasalo R, et al. Depression and anxiety in early pregnancy and risk for preeclampsia. Obstet Gynecol 2000;95:487-90.

http://dx.doi.org/10.1016/S0029-7844(99)00602-X

22. Bennett HA, Einarson A, Taddio A, et al. Prevalence of depression during pregnancy: systematic review. Obstet Gynecolo 2004;103:698-709.

http://dx.doi.org/10.1097/01.AOG.0000116689.75396.5f

23. Yücel $P$, Çayır $Y$, Yücel M. Birinci Trimester Gebelerde Depresyon ve Anksiyete Bozukluğu. Klinik Psikiyatri 2013;16:83-87.

24. Da Costa D, Larouche J, Dritsa M, et al. Psychosocial correlates of prepartum and postpartum depressed mood. J Affect Disord 2000;59:31-40. http://dx.doi.org/10.1016/S0165-0327(99)00128-7
25. Çakyır L, Can H. Gebelikte sosyodemografik değişkenlerin anksiyete ve depresyon düzeyleriyle ilişkisi. Turkish Family Physician 2012;3:35-42.

26. Lee AM, Lam SK, Sze Mun Lau SM, et al. Prevalence, course and risk factors for antenatal anxiety and depression. Obstet Gynecol 2007;110:1102-1112. http://dx.doi.org/10.1097/01.AOG.0000287065.59491.70

27. Akbaş E, Vırıt O, Kalenderoğlu A, et al. Gebelikte sosyodemografik değişkenlerin kaygı ve depresyon düzeyleriyle ilişkisi. Nöropsikiyatri Arşivi 2008;45:85-91.

28. Caliskan D, Oncu B, Kose K, et al. Depression scores and associated factors in pregnant and non-pregnant women: $A$ community-based study in Turkey. Journal of Psychosomatic Obstetrics \& Gynecology 2007;28:195-200. http://dx.doi.org/10.1080/01674820701450649

29. McFarland J, Salisbury AL, Battle CL, et al. Major depressive disorder during pregnancy and emotional attachment to the fetus. Arch Womens Ment Health 2011;14:425-434. http://dx.doi.org/10.1007/s00737-011-0237-z 